We thank our nursing, technical, and medical colleagues for cooperation, and $\mathrm{Mr} \mathrm{K}$ Matthews for the statistical analysis.

\section{References}

1 Beard, R W, et al, fournal of Obstetrics and Gynaecology of the British Commonwealth, 1971, 78, 865.

2 Caldeyro-Barcia, R, The Heart and Circulation in the Newborn and Infant, p 7. New York, Cassell, 1966.

${ }^{3}$ Kubli, F W, et al, American fournal of Obstetrics and Gynecology, 1969, 104, 1190.

${ }^{4}$ Wood, C, et al, American fournal of Obstetrics and Gynecology, 1969, 105, 942.

${ }^{5}$ Cooper, J M, Soffronoff, E C, and Bolognese, R J, Obstetrics and Gynecology, $1975,45,27$.
'G Gaziano, E M, Hill, D L, and Freeman, D W, American fournal of Obstetrics and Gynecology, 1975, 121, 947.

'Schifrin, B, et al, ()bstetrics and Gynecology, 1975, 45, 433.

'Weingold, A B, de-Jesus, T P S, and O'Keiffe, J, American fournal of Obstetrics and Gynecology, 1975, 123, 466.

${ }^{9}$ Kubli, F W, Kaeser, I, and Hinslemann, M, The Feto-Placental Unit, p 323. Amsterdam, Exerpta Medica, 1969.

10 Hammacher, K, Perinatal Medicine, p 80. New York, Academic Press, 1970.

${ }^{11}$ Rochard, F, et al, American fournal of Obstetrics and Gynecology, 1976, 126, 699 .

12. Emmen, L, et al, British fournal of Obstetrics and Gynecology, 1975, 82, 353.

${ }_{13}$ Dreyfus-Brisac, C, and Blanc, C, Encéphale, 1956, 45, 205.

14 Laversen, N H, Hochberg, H M, and George, M E D, American fournal of Obstetrics and Gynecology, 1976, 125, 1125.

\title{
Sex-related differences among 100 patients with alcoholic liver disease
}

\author{
MARSHA Y MORGAN, SHEILA SHERLOCK
}

British Medical fournal, 1977, 1, 939-941

\section{Summary}

During 1975 we studied 100 patients -77 men and 23 women-who had a history of alcohol abuse and disturbed liver function test results. On presentation the women were less likely to be suspected of alcohol abuse $(9 ; 38 \%)$ than the men $(59 ; 77 \%)$. Although the quantity of alcohol consumed and length of history of alcohol abuse were similar for men and women, the incidence of chronic advanced liver disease was higher among women $(86 \%)$ than among men $(65 \%)$. Women, however, were less likely to have developed primary liver cell cancer. Overall the women had a higher incidence of other alcohol-related disorders and were less likely to stop abusing alcohol $(2 ; 9 \%)$ than were their male counterparts $(22 ; 29 \%)$. Women seem to be more susceptible to alcohol-related disease.

\section{Introduction}

In 1945 Spain $^{1}$ reported that women with alcoholic cirrhosis died younger than men, and that death among women was usually secondary to hepatocellular failure, whereas in men it was related to portal hypertension. Since then few studies of alcohol-related liver disease have taken into account sex differences. ${ }^{2-6}$ We therefore studied the drinking patterns, presentation, clinical picture, and prognosis in men and women seen at The Royal Free Hospital, London, (RFH) during 1975 who had a history of alcohol abuse and disturbed liver function test results.

\section{Patients and methods}

The medical unit at RFH has a special interest in hepatology, and the hospital, by virtue of its geographical situation, draws a fairly

Department of Medicine, Royal Free Hospital, London NW3 2QG MARSHA Y MORGAN, MB, MRCP, honorary lecturer in medicine SHEILA SHERLOCK, MD, FRCP, professor of medicine high percentage of its patients from the upper social classes. Both these factors affected the characteristics of the population in this study.

During 1975516 patients with liver disease were admitted to the medical unit. All were interviewed and 100 were identified as alcohol abusers, drinking regularly above $100 \mathrm{~g}$ of ethanol per $\mathrm{kg}$ body weight per day. This level of consumption, if sustained, carries the risk of physical complications." Socioeconomic circumstances and drinking habits were recorded, social class being defined by occupation ${ }^{7}$ and highest class achieved. Married women were classed according to their husband's occupations. A family history of alcoholism was sought. The age of onset of regular drinking and of regular heavy drinking was recorded, and so far as possible the type and amount of beverage consumed per day were assessed. Patients were judged to be physically dependent on alcohol if they gave a history of tremor after a period of abstinence, which was relieved by alcohol, and of episodes of amnesia. The nccurrence of episodes of delirium tremens-characterised by disorientation, delusions, visual hallucinations, and fear and accompanied by restlessness, hyperactivity, and possibly epileptiform fitswere noted. Percutaneous liver biopsy was performed in all patients except three.

While in hospital patients were forcefully and repeatedly warned of the dangers of alcohol abuse. After discharge these warnings were repeated at regular outpatient attendances. Blood ethanol concentrations were a valuable guide to continuing alcohol abuse. ${ }^{8}$ All patients were referred to their general practitioners and when necessary to social services. Alcoholics Anonymous was discussed. Only $9^{\circ}{ }^{\circ}$ of the patients were thought to require consultant psychiatric help at the start of the study. Patients alive at the end of the year were reviewed. Data were analysed using the $2 \times 2 \%^{2}$ test, Fisher's exact probability test, or the Mann-Whitney U test. ${ }^{10}$

\section{Results}

The 100 patients $(77$ men and 23 woman) who were identified as alcohol abusers accounted for $19 \cdot 4^{\circ}{ }_{0}$ of the total admissions for liver disease. In $69^{\circ}$, alcohol abuse had been suspected at first presentation whether at RFH or elsewhere. Women were less likely to be suspected of alcohol abuse $\left(9 ; 38^{\circ}{ }_{0}\right)$ than men $\left(59 ; 77_{0}^{\circ}\right)(\mathbf{P}<0.001)$. Two case histories of women patients illustrate this point.

\section{CASE 1}

In April 1974 after a flu-like illness a 34-year-old married African State Registered Nurse became jaundiced, with dark urine and light stools. This was accompanied by pain in the right upper abdomen and pruritus. Her 30 -year-old brother had recently died of alcoholic cirrhosis. She denied 
alcohol abuse. (A percutaneous liver biopsy was reported as micronodular cirrhosis, probably biliary in origin, with ascending cholangitis and severe fatty change.) At laparotomy the gall bladder contained a single stone and was removed. An operative cholangiogram showed normal ducts.

In January 1975 she was readmitted with anorexia, weight loss of $20 \mathrm{~kg}$, and return of jaundice. She deteriorated rapidly and was transferred to the RFH. She had gross hepatosplenomegaly and ascites. The liver biopsy report from 1974 was reviewed and interpreted as cirrhosis with severe alcoholic hepatitis. She admitted that she had been drinking three-quarters of a bottle of sherry per day for the last seven years, but emphasised that previously she had never been questioned concerning alcohol intake.

\section{CASE 2}

For two years a 57-year-old woman doctor married to a general practitioner had suffered recurring bouts of anorexia, nausea, and shivering. She had seen seven consultant physicians and each had diagnosed only depression. She had received electric convulsion therapy. In July 1974 while on holiday she became extremely tremulous and had a grand mal fit, presumably secondary to alcohol withdrawal. Her husband became suspicious of her alcohol intake and sent her to a new general practitioner, who found hepatomegaly. He referred her to the RFH, where in January 1975 a liver biopsy showed severe alcoholic hepatitis. She and her husband refused further help, preferring to cope with the problem together.

Of the patients, 49 men $(64 \%)$ and 16 women $(69 \%)$ were married or remarried; $18 \%$ of both sexes were divorced-a rate of divorce no higher than that of the country as a whole. ${ }^{9}$ In Great Britain $25 \%$ of the population are of social Classes I or II $^{9}$ - the professional and higher managerial classes. Many of the patients in this study were of social class $\mathrm{I}$ or $\mathrm{II}-40(52 \%)$ men and $13(58 \%)$ women. Of both sexes $20 \%$ worked in the hotel and catering trade, but "business executives" comprised the highest percentage of the male patients $(35 ; 46 \%)$ and "housewives" the highest percentage of the female admissions (12; $52 \%$ ). Half of the men and $67 \%$ of the women had a positive family history of alcohol abuse.

Patients of both sexes began to abuse alcohol at a similar agethe mean age for men was 29.2 years (range 17-57 years), and for women 33 years (range 14-63 years). Women of the higher social classes tended to start drinking at a later age. The amount of alcohol consumed/kg body weight/day was difficult to assess but all the patients had been drinking over $100 \mathrm{~g}$ ethanol daily for at least three years. The pattern of abuse was similar, usually constant imbibing, only two men being "binge" drinkers. Although the quantity consumed was similar, the beverages favoured differed between the sexes. Fifty-nine of the men $(77 \%)$ and $16(70 \%)$ of the women drank predominantly spirits (gin, vodka, whisky, brandy). Fourteen of the men $(18 \%)$ drank beer only compared with only one of the women $(4 \%)$, while five $(7 \%)$ of the men drank fortified wines (sherry and martini) compared with six $(26 \%)$ of the women. Overall, $2 \%$ of the group drank wine exclusively. In both sexes cheaper beverages were favoured by those in the lower social classes.

The mean age at presentation for the men- $47 \cdot 3$ years (range 23-74 years)-was not statistically different from that of the women47.9 years (range 16-72 years). Similarly the mean length of history of alcohol abuse among the men-20.4 years (range 3-52 years) did not differ statistically from that among the women-16.8 years (range 3-40 years).

The commonest mode of presentation was a raised aspartate transaminase (AST) concentration with or without hepatomegaly (table I). Among the men this was often found during a routine medical insurance examination. Thirty per cent of women presented with hepatocellular failure (jaundice, ascites, peripheral oedema). Seven male patients $(9 \%)$ presented with gastrointestinal bleeding but in only one patient was this from oesophageal varices.

Although results of liver function tests for all patients were abnormal, biopsy findings were normal for nine men $\left(12^{\circ} \%\right.$ ) (table II). Sixty per

TABLE I-Modes of presentation of 75 male and 22 female alcoholics

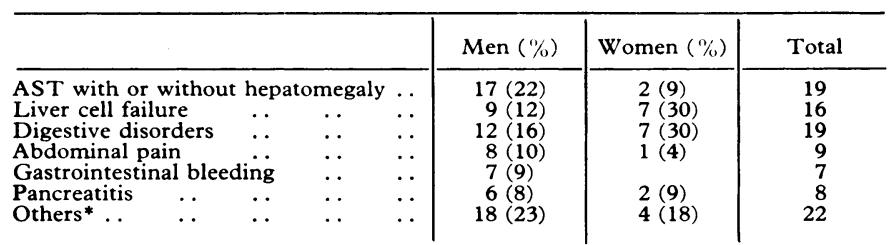

* Of this group 5 patients presented after collapse or accident; 6 with neurological complications; 4 with peptic ulceration; 4 with skin disease; and 3 with either
anaemia, or backache, or heart failure. AST $=$ raised aspartate transaminase concentration.
TABLE II-Liver biopsy findings among 75 male and 22 female alcoholics

\begin{tabular}{|c|c|c|c|}
\hline \multicolumn{2}{|c|}{ Liver histology } & Men $(\%)$ & Women $(\%)$ \\
\hline 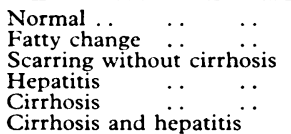 & $\begin{array}{ll}\because & \cdots \\
\because & \cdots \\
\cdots & \cdots \\
\cdots & \cdots \\
. & \cdots\end{array}$ & $\begin{aligned} 9(12) \\
13(17) \\
4(6) \\
8(10) \\
27(36) \\
14(19)\end{aligned}$ & $\begin{array}{l}2(10) \\
1(5) \\
3(14) \\
9(38) \\
7(33)\end{array}$ \\
\hline
\end{tabular}

TABLE III-Different types of alcohol-related disorders found among 77 male and 23 female alcoholics

\begin{tabular}{|c|c|c|c|}
\hline Type of disorder & & Men $(\%)$ & Women $(\%)$ \\
\hline 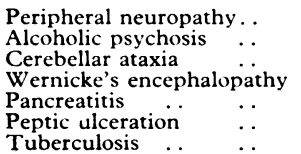 & $\begin{array}{ll}\cdots & \cdots \\
\cdots & \cdots \\
\cdots & \cdots \\
\cdots & \cdots \\
\cdots & \cdots \\
\cdots & \cdots\end{array}$ & $\begin{aligned} & 22(29) \\
& 2(3) \\
& 2(3) \\
& 4(5) \\
& 10(13) \\
& 14(18) \\
& 9(12)\end{aligned}$ & $\begin{aligned} & 13(57) \\
& 3(13) \\
& 3(13) \\
& 2(9) \\
& 4(17)\end{aligned}$ \\
\hline
\end{tabular}

cent of the group had cirrhosis with or without alcoholic hepatitis. The women showed a higher incidence of more severe liver disease; $86 \%$ had hepatitis with or without cirrhosis as compared with $65 \%$ of the men. Five of the 41 men with cirrhosis $(12 \%)$ developed primary liver cell cancer. Three of these patients had stopped drinking alcohol four, five, and seven years previously. None of the women developed primary liver cell cancer.

Physical dependency on alcohol was noted among $65 \%$ of patients of both sexes. Twenty per cent of the patients gave a history of delirium tremens. There was no relation between the length of history of alcohol abuse and dependency, nor between the severity of the liver lesion and dependency. Overall, there was a higher incidence of other alcohol-related disorders among women, although none of the women developed peptic ulceration or tuberculosis (table III). Peripheral neuropathy and peptic ulceration were associated with more advanced liver disease but pancreatitis was not.

At the end of the year 10 men $(13 \%)$ and five women $(22 \%)$ had died. There was no common mode of death. All these patients had cirrhosis with or without hepatitis, and two of the men had primary liver cell cancer. The mean ages at death for men and women59.3 years and 46.8 years respectively-and the length of history of alcohol abuse were similar. ${ }^{10}$ Seventy-six patients were continuing to abuse alcohol at the end of the year. The women were significantly less likely to stop drinking $(2 ; 9 \%)$ than were the men $(22$; $29 \%)(P<0.05)$. Patients with cirrhosis were more likely to stop drinking than were patients with less advanced liver disease $(P<0.005)$.

\section{Discussion}

More patients are being referred with alcoholic liver disease. Ten years ago about 30-40 patients were admitted each year to our unit with alcohol-related liver disease. ${ }^{4}$ Last year 100 such patients were admitted. This reflects the increased incidence of alcohol abuse in Great Britain in recent years, and its role as a major cause of liver damage.

The male : female ratio of alcoholics agrees with that given by Glatt $^{11}$ for alcoholics in Great Britain. Women are less likely to be suspected of alcohol abuse, even if they develop withdrawal symptoms in hospital. There are several reasons for this. Because of social stigma a woman is less likely to admit to alcohol abuse. She also has much greater opportunities to "cover up." If she drinks at home alone during the day her family are often unaware of her problem, as she has usually "sobered up" by the time they arrive home in the evening. The family of the female alcoholic may therefore deny her alcoholism to her doctors, an attitude rarely encountered in the relativies of male alcoholics. Finally, doctors have a much lower index of suspicion for alcohol abuse in women and are often repeatedly "taken in" by the highly plausible female alcoholic. This is well illustrated by the case histories cited. The divorce rate was the same for men and women and similar to that of the whole country. This is at variance with Glatt's findings, ${ }^{11}$ who noted 
that the husbands of alcoholic women were more likely to leave their wives than were the wives of alcoholic men to leave their husbands. This is of great importance because it means that a high percentage of our patients have a degree of background stability.

The high incidence of patients in the higher social classes is in part a feature of population selection because of the location of the RFH in Hampstead, London. Men in the higher social classes also often undertake private medical insurance examinations so that there is a high "pick-up" rate of asymptomatic alcoholics from this group. The high incidence of a positive family history accords with that found in many other series. Nylander, ${ }^{12}$ for example, showed that sons of alcoholics have a much higher incidence of alcoholism than other men of the same age. Differences in the type of beverage consumed reflect social conventions. Women generally do not drink beer but favour fortified wines, gin, or vodka. Men prefer beer, whisky, or brandy. Cost also determines the beverage chosen, and availability is important. Many women who would previously not have visited an off-licence will quite happily buy alcohol from the supermarket with the family shopping.

The length of history and the age at presentation were similar for both sexes. Women presented with more established disease, which suggests that they develop cirrhosis after a shorter period of alcohol abuse. Caroli and Pequignot, ${ }^{2}$ found that women developed cirrhosis at a lower level of alcohol intake than men. Wilkinson et $a l^{3}$ in Melbourne found alcoholic cirrhosis twice as often in women. The women had a shorter history of alcohol abuse and this suggested that they were more susceptible to alcoholic liver damage.

Of the patients with alcoholic cirrhosis, five of the men but none of the women developed primary liver cell cancer. Lee ${ }^{13}$ found that the incidence of primary liver cell cancer was highest among patients who had given up alcohol and who had developed a coarsely nodular cirrhosis. He suggested that women often continued drinking until death and so the cirrhosis remained micronodular. This explained their low risk of developing primary liver cell cancer. In our series three of the five men who developed this tumour had given up alcohol several years ago. In contrast to the findings of Wilkinson et al, ${ }^{14}$ and of Brunt ${ }^{4}$ there was a much higher incidence of other alcohol-related disorders among women. The female alcoholic appears more susceptible not only to liver damage but also to other types of alcohol-related physical injury.

The age at death and the mortality rates were similar for both sexes, confirming the results of Powell and Klatskin, ${ }^{5}$ and Brunt. ${ }^{*}$ Others have shown that women die from alcoholic liver disease at a younger age than men. ${ }^{16}$ Women alcoholics are generally regarded as more difficult to treat than men, and this is supported by the significantly higher number who continued to abuse alcohol. Many of these women were bored and lonely housewives without a career, who return after discharge from hospital to an environment in which they are largely unsupervised. Efforts must be made to find these women employment, if only voluntary, to take them out of their home environment.

Our findings suggest that women are more susceptible to alcohol-related diseases, particularly liver disease. Their condition is less easily diagnosed and more difficult to treat. Early diagnosis of alcoholism is of utmost importance. More vigilance and a higher degree of suspicion of possible alcohol abuse among female patients is needed.

\section{References}

1 Spain, D M, American fournal of Clinical Pathology, 1945, 15, 215.

2 Caroli, J, and Pequignot, G, in Proceedings of the Third World Congress of Gastroenterology, vol 1, p 661. Baltimore, Williams and Wilkins, 1958.

3 Wilkinson, P, Santamaria, J N, and Rankin, J G, Australasian Annals of Medicine, 1969, 18, 222.

${ }^{4}$ Brunt, P W, et al, Gut, 1974, 15, 52.

${ }^{5}$ Powell, W J, jun, and Klatskin, G, American fournal of Medicine, 1968, 44, 405.

${ }^{6}$ Galambos, J T, Alcoholic liver pathology. Ontario, Addiction Research Foundation, 1975.

${ }^{7}$ Office of Population Censuses and Surveys, Classification of Occupation 1970, London, HMSO, 1971.

${ }^{8}$ Hamlyn, A N, et al, Lancet, 1975, 2, 345

9 Central Statistical Office, Social trends 1973 , no 4 . London, HMSO, 1973

10 Siegel, S, Non-Parametric statistics for the behavioral sciences. New York, McGraw-Hill, 1956.

11 Glatt, M, The Alcoholic and the help he needs. London, Priory Press, 1972.

12 Nylander, I, Acta Paediatrica Scandinavica, 1960, 49, supplement 21.

13 Lee, F I, Gut, 1966, 7, 77.

14 Wilkinson, P, et al, Medical fournal of Australia, 1971, 1, 1217.

(Accepted 9 February 1977)

\title{
Anaesthetic waste gas scavenging systems
}

\author{
R F ARMSTRONG， E J KERSHAW，S P BOURNE， L STRUNIN
}

British Medical fournal, 1977, 1, 941-943

compared to see how effectively they reduced concentrations of halothane in the atmosphere. All five systems reduced halothane levels significantly, the combination of an active system and semiclosed circuitry being the most effective. All obvious leaks from equipment were controlled in this study, but normally such leaks contribute significantly to atmospheric pollution. Some of the benefits of a scavenging system may be lost if gases can still escape through leaks.

\section{Introduction}

Depart

R F ARMSTRONG, MB, FFA RCS, consultant anaesthetist

$S$ P BOURNE, MB, FFA RCS, senior registrar

Department of Anaesthesia, King's College Hospital, London SE5

E J KERSHAW, MB, FFA RCS, senior registrar

L STRUNIN, MD, FFA RCS, professor

Various epidemiological studies have suggested an association between atmospheric pollution by anaesthetic gases and vapours and toxic effects in operating theatre staff. ${ }^{1-4}$ Volatile and gaseous agents are an integral part of general anaesthesia, and waste gases escape into the atmosphere of the operating area. Although leaks may occur from anaesthetic apparatus and 